\title{
Research on the Influence of Forced Submissiveness on the Behavior and Attitude
}

\author{
Guang XU, Yu-Chao WANGa , Xue ZHANG \\ Harbin Normal University \\ ajerry4m@126.com
}

Keywords: Forced submissiveness, Attitude change, Success expectation, Conformity.

\begin{abstract}
The study of attitude and behavior has always been a very important issue on social psychology. Based on Theory of cognitive dissonance, Theory of Reasoned Action and The theory of planned behavior, study the relationship between the submissiveness, behavior attitude and Conformity under the influence of the power. Further analyzes the function of the success expectations moderated the process of attitude change. The results of this research show that the forced submissiveness can promote members to generate cognitive dissonance, under the influence of high success expectations, the attitude change may caused by cognitive dissonance, then bring about the submissiveness. Under the low success expectations situation, cognitive dissonance may result in the individual distorted reality or selectively explaining inconsistent information to reduce cognitive dissonance, so that cannot bring about submissiveness.
\end{abstract}

\section{Introduction}

Behavior and attitude is not always consistent, under a complex social environment, individuals were affected by external forces, and cannot acting according to self attitudes, and one of the best examples is the military forced submissiveness. Whether individual attitude changes after forced submissiveness, Festinger studies suggest when individual behavior do not consistent with the original attitude, individual will fell cognitive dissonance, this emotional experience drives individuals try to reduce or eliminate the inconsistency emotional experience, there are three ways: (1) Change behavior, behavior conform to the original attitude; (2) Change of attitude, make it conform to behavior; (3) The introducing of new cognitive elements, so that changes not harmonious situation[1], this theory has proved that behavior can change your attitude.

Behavior attitudes has changed, the individual will show more initiative in its behavior, this kind of behavior standards is internalized into the value system of itself, thus it was formed the submissiveness [2]. However, research which the individual psychological change process of submissiveness leads to Conformity is quite few. The purpose of this study is that to study the attitude of changes in the process of forced submissiveness, in order to product Conformity. In additional, we have tested the individual psychological expectation as a moderate function in the process of behavior change.

\section{Establishment of a conceptual model}

\section{Research of behavior attitude effects on the behavioral intention}

Theory of Rational Action was first proposed in the 1970s by the American scholar M. Fishbein and L. Ajzen, this theory emphasize cognitive factors have an important role in changes of individual health behavior, ethical behavior, and other behavior. The theory holds that human behavior has the characteristics of Rationality. Behavior intention is the most important forecast factors cause behavior change and which directly determine behavior change [3]. AJzen further study (Theory of Planned Behavior) proves that people's behavior intention will be affected by behavior attitude [4]. The behavior attitude refers to an individual's overall evaluation of a behavior, which includes two components: Beliefs of the behavior results will be bring about and the evaluation of behavior Consequences after involve in a certain behavior [3]. In short, the change of 
the individual behavior attitude will cause the change of the corresponding behavioral intention, and then lead to behavior emerging.

\section{Research on behavior attitude diversification under forced submissiveness effect}

When individual was forced to obey the behavior of organization requirements, this is called forced submissiveness which was brings about by cognitive dissonance. The motivation of people will become stronger, when people want to reduce or eliminate not harmonious relationship [1]. Research proves that there are two kinds of ways reducing dissonance, named facing mechanism and avoiding mechanism. Facing mechanism by changing the cognitive factors of dissonance to reduce the one, such as changing attitude, reduce the ego involvement degree, changing behavior etc; Avoiding mechanism refers to the individual distorting reality or selectively explaining inconsistent information to reduce the imbalance emotion felling, such as denying, distort, denigrate inconsistent information[5].

In forced submissiveness circumstances, individual will have cognitive dissonance of emotional experience. After the assessment based on the reality and existing experience of the past, the individual will produce high success expectations to this behavior, He thinks this behavior must be get succeed, the individual desire to get the result of behavior, which will cause a high motivation[8][9]. This time individual adopt facing mechanism, which is, changing the attitude of a certain behavior to reduce the dissonance, thus promote the generation of positive results. An individual in low success expectation expectations, and the results of behavior and the possibility of the behavior getting success in a lack of confidence, who will take avoiding mechanism, finding reasonable explanation to maintain the original attitude, still showing the submissiveness [6]. This study explains the theory of $\mathrm{H}$. Kelman: attitude of individual was formed and changed [7].

\section{Establishment of the concept model on forced submissiveness lead to Conformity}

On the basis of above discussion, under the high expectations, forced submissiveness can lead to the changing of behavior attitude, this kind of attitude change will cause subject adopt the object's behavior or attitudes as the standard of concept \& judgment and reasoning, then producing the behavior or attitude is consistent with the object, which was called conformity. Under low expectations circumstance, individual will seem the behavior as" The requirements of others", The process of behavior is passive, emotional experience is negative [2][8]. As shown in figure 1, This study holds that the emergence of Conformity needs a process of transform from submissiveness to Conformity.

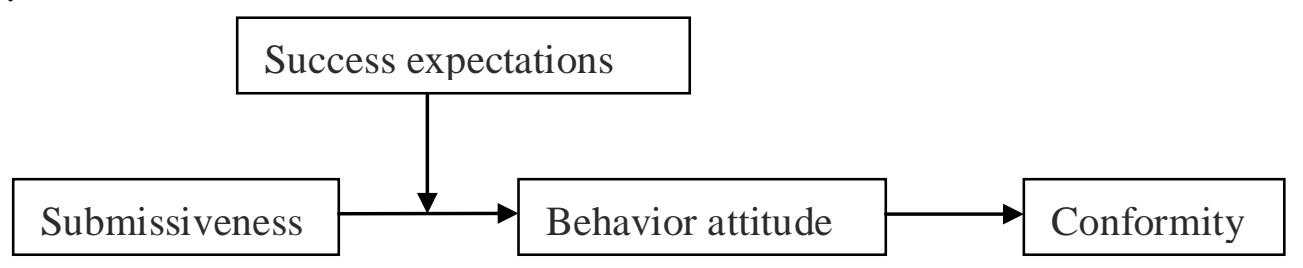

Figure.1 The Concept Model

\section{The establishment of theoretical model}

\section{Analysis of the relationship between forced submissiveness and Conformity}

According to the definition of Taylor et al : "Submissiveness is the faith of the authority which was required by power" [9]. Basis On this theory, the Festinger. L defended force submissiveness as a surface submissiveness along with inner view no change, this kind of surface submissiveness by punitive threats or promise to give reward [10]. The study found that the power distance of China are higher than one of most western countries [11], more easy to produce submissiveness. When subject under the fuzzy or objective of psychological situation, forced submissiveness makes members of the organization to do the same behavior, under the influence of group pressure and homoplasy Psychology, members of the organization gradually according to the standard of behavior as a concept, judgment and reasoning, at this time, submissiveness transform into 
Conformity. So this way is easy to alter the behavior of members in the organization which is more directly and effectively.

\section{Analysis of Mediating Effects about attitude and behavior}

Attitude is a kind of psychological tendency, it is based on evaluation of a certain degree of like or dislike performance to the specific object [12]. Based on this, Fishbein and Ajen Theory of Rational Behavior (TRA) is divided attitude into two parts: attitude towards an object (Ao) and attitude towards behavior (Aact). The behavior attitude refers to a person's attitude to perform specific actions in a given environment. Their research also confirmed that in certain circumstances, a person's behavior attitude has positive influence on promoting the behavioral intention, which will leads to the corresponding behavior [3].

\section{Analysis of success expectation regulating effect}

Affect of Expectations on people behavior motivation. Expectation is a moderator variable, affect the relationship between the work supply and work results [13]. Expectations of success, refers to oneself assessment of the individual's performance in a given task[14], and high expectations can lead to high motivation of success, thus promote the generation of positive results[15]. Victor H.V room's research shows that when a person select a solution multiple feasible solutions in the unpredictable circumstance, the individual subjectively assess the value of the results of behavior, tend to adopt attitude which can lead to the best results, refused to accept attitude that can lead to bad results. His behavior is not only influenced by its preference of expectation, and influence by the possible of realization of these results [6].

Under the influence of success expectation, analysis on cognitive changes of the individual. Cognitive gestalt was a closed box, self-regulatory and instinctive resistance to different information, so as to make the attitude is not easy to change. Only when the external information caused the larger gap can't self make up perceptions, this large gap could lead to the collapse of their original cognitive gestalt. Under this situation, the individual may accept persuade information to establish a new cognitive gestalt, resulting in the corresponding change of structure of the attitude (M. Ertheimer, K.K Offka, Warren Koziren Skiohler, 1913, 1917). When success expectation is stronger, due to positive expectation of the results of behavior, individuals under the influence of high motivation after feel cognitive dissonance, it would accept the new cognition so that to compensate for the cognitive gap, which directly caused attitude internalization. When individual feel lower success expectation, individual hold negative expectations of behavior results [6][16][17], will be looking for new cognitive reasonable explanation for the inconsistence between original attitude and behavior, in order to maintaining the original attitude or low cognitive dissonance or without dissonance[10][18], which will strengthen the original attitude.

\section{The positive effects of success expectation influence on the behavior.}

Research hold that success expectations that contains both components of self-efficacy expectations and results expectations, Influenced by the task characteristics and individual's self-ability concept [19]. The results expectations refer to some kinds of behavior can generate the desired results, and self-efficacy expectations refer to the individual can show certain behavior in the certain circumstance [20]. Classic motivation theory tell us that people's high success expectations can lead to high motivation [15], under the influence of high motivation, subject will change his behavior attitude or behavior intention. 


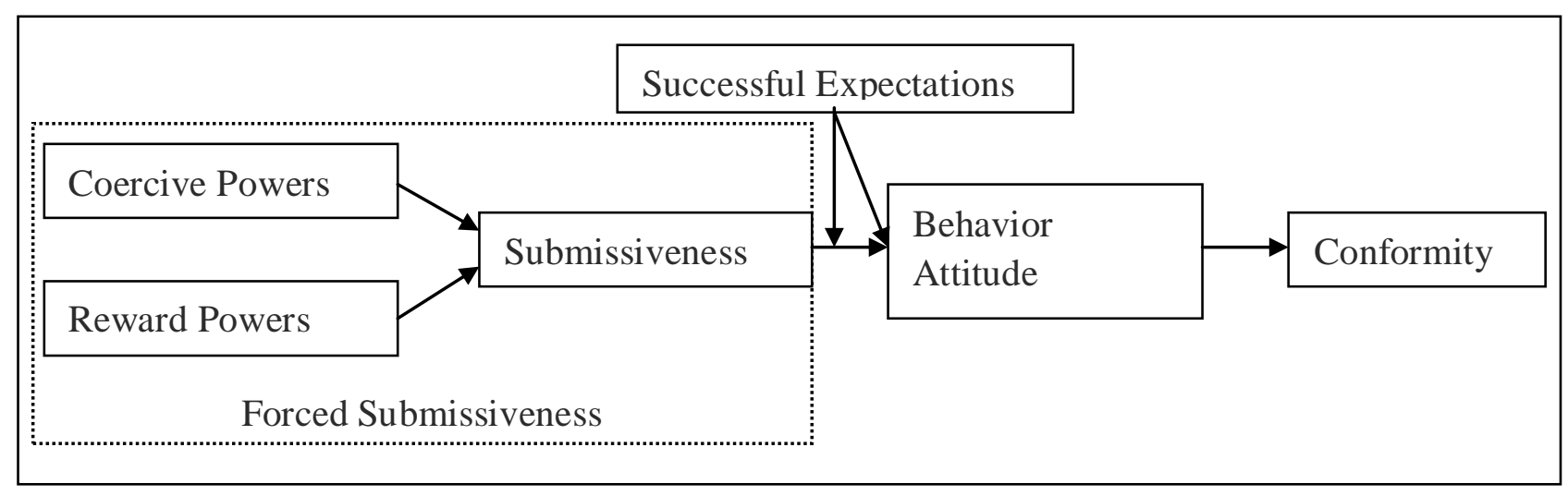

Figure.2 The theoretical model

\section{Forced obedience model under the action of an individual attitude and behavior change}

Above all, under the influence of conceive power or reward power, individuals would show submissiveness, what is known as the forced submissiveness. The traditional view hold that forced submissiveness has a negative effect on attitude, but this study thinks that forced submissiveness would cause cognitive dissonance, under the influence of high success expectations, which can lead to the change of behavior attitude, individuals adopt the behavior as their own standard of concept, judgment and reasoning, its process of behavior are initiative, emotional experience is positive, the behavior is submissiveness. Under low expectations situation, it will strengthen the original attitude, so it brings about Conformity.

\section{Conclusion}

We analyze the individual, it not difficult to find. When individuals force to do something but he or she dislike it. His heart will endure the pressure which would produce cognitive dissonance. At this time, he may be looking for a good reason to support their inconsistent behavior and attitudes. One case, he found the external grounds to support his actions sufficiently; another situation is that he has no external grounds or insufficient grounds, individuals can't ease the pressure inside of it. Research of psychologists found that the pressure for the former eliminate by the outside grounds, attitude of individual inconsistent with behavior, which was named avoidance mechanisms; for the latter, because no way to release the pressure, his attitude will be change, that was called faced mechanism. This feedback can be understood as a protective mechanism that people have evolved before.

This composition shows that when individuals are forced to obey, they will psychologically suffer emotional stress of cognitive dissonance. If an organization gives the individual high expectations, the high expectations can cause the individual to conduct a strong desire to produce the desired results and a belief to achieve the results. The self-efficacy expectations and results expectations in high level which will give individual a positive emotional experience and emotional attitude will change rapidly. In addition, the expectations of results will lead to individuals to produce stronger motivation on the behavior. Self-efficacy expectations mean the belief to achieve the results, which will accelerate the change of cognitive attitudes. After changing attitudes, the individual will show more initiative and enthusiasm on this behavior that was conformity. If under the low and successful expectations, attitudes will not change, and the behaviors will be maintained as submissiveness, the original attitudes structure will be enhanced.

This study provide a solutions for the organization to change the behavior of members and provides the basis principle for the organization's managers to reasonably force the members to obey, facilitate the rapid assimilation of new staff, in order to reduce the cost of tissue fusion. This study has investigated the impact of members' success expectations. Future research should be strengthened in researching the factors of organizations, such as how the peer pressure, a sense of 
organizational effectiveness, psychological factors' influence on staff's submissiveness, which need more academics' research to improve.

\section{Acknowledgement}

This research was financially supported by the National Science Foundation" "Network Public Opinion Oversight Mechanisms Research on Citizenship Behavior and Its Dynamic Evolution Mechanism" (11BGL013); "Harbin Normal University Academic Missions Projects" (XYZ2011-13).

\section{References}

[1] Festinger L, (1962), A theory of cognitive dissonance, Stanford university press.

[2] Song Guandong, (2004), Conformity investigation behavior, Psychological Science, 27 (3): 657-661.

[3] Fishbein M, Ajzen I, Belief, Attitude, Intention and Behavior, an introduction to theory and research, Mass: Addison-Wesley, (1975), pp.11- 561.

[4] Ajzen I, (1991), The theory of planned behavior, Organizational behavior and human decision processes, 50 (2): 179-2111.

[5] Kalman, J.KaPlan, (1972), From Attitude Formation to Attitude Change: Acceptance and impact as cognitive mediators, Soeiometry, 35(3): 448-467.

[6] Su Dongshui. Management Psychology, Beijing: Fu Dan University Press, (2002), pp.148-150.

[7] Cheng Zhengfang, Management Psychology, Beijing: Beijing Normal University Press, (1996), pp.191-192.

[8] Atkinson, J. W., (1957), Motivational determinants of risk taking behavior, Psychological Review, (64): 381-390.

[9] Shelley E. Taylor, Letitia Anne Peplau, David O. Sears. Social Psychology (English). Peking University Press, (2004), pp.224.

[10] Festinger L, Cognitive dissonance theory (in Chinese), Hangzhou: Zhejiang Education Press, (1999),pp.14 19

[11] Huobao Feng, Han Zhaojun, Zhao Xiande, (2013), power and influence on relationship commitment supplier integration, Journal of Management Science, 16 (4): 33-50.

[12] Krech D, Crutchfield R S, Ballachey E L, Individual in society: A textbook of social psychology, 1962.

[13] Marshall, M. A., Brown, J. D., (2004), Expectations and realizations: The role of expectancies in achievement setting, Motivation and Emotion, 28, 347-361.

[14] Eccles, J. Expectancies, values, and academic behaviors, In J. T. Spence (Eds.), Achievement and achievement motives, San Francisco: Freeman, (1983), pp.75-146.

[15] Atkinson, J. W, (1957), Motivational determinants of risk taking behavior, Psychological Review, 64: 381-390.

[16] Oettingen, G, (2000), Expectancy effects on behavior depend on self-regulatory thought, Social Cognition, 18: 101-129.

[17] Oettingen, G., Mayer, D, (2002), The motivating function of thinking about the future: expectations versus fantasies, Journal of Personality and Social Psychology, 83: 1198-1212. 
[18] Martin Bettina, (1973), Reduction of Cognitive Dissonance as a Function of Magnitude of Dissonance, Differentiation and Self-esteem, European Journal of Social Psychology, 3(3): 255-270.

[19] Dickhäuser, O., Reinhard, M, (2006), Factors underlying expectancies of success and achievement: the influential roles of need for cognition and general or specific self-concepts, Journal of Personality and Social Psychology, 90:490-500.

[20] Bandura, A., Self-efficacy: The exercise of control, New York: Freeman, 1997. 